\title{
De alternativa inmediata a fermento a largo plazo
}

\author{
José Ignacio González Faus \\ Facultad de Teología de Cataluña, \\ Centro de Reflexión Teológica.
}

Es pretencioso querer ofrecer unas conclusiones hoy mismo. Quizás sería más urgente pedir perdón por los fallos del cncuentro, por las ausencias que alguicn puede haber detectado de latinoamericanos a los que no pudimos invitar $y$, a la ve $\%$, por el recargamiento y la intensidad de algunos días en que casi no se les ha dcjado respirar. Todo ello se dcbe a que el encuentro se ha hecho con premuras notables de tiempo y dinero. Tanto que estuvo a punto de no celebrarse (por eso se anunció un poco tarde), y sólo la paciencia y la constancia de Antonio Blanch lograron salvarlo del naufragio.

En medio de estos días tan variados y tan complejos, mi sclección ha tenido que ser muy rápida y es desde luego muy provisional. He oplado por ser más claro que completo. Y no la ofrezco para imponer o suplanlar las conclusiones que cada cual deberá sacar del encuentro, sino por si puede ayudar a esa tarea. Para que, al irnos, no demos ya por clausurado nuestro congreso, sino comprendamos que ha sido algo tan incipiente y tan abigarrado, que ahora tenemos que comenzar a digcrirlo. Esta será la manera de que el congreso no mucra hoy.

Con cl ạán de ser sobre todo claro, y dado que el hilo conductor del congreso se había tcjido sobre cl paso de veinte años entre el 72 y el 92 , se me ha ocurrido sistematizar este csbozo de conclusiones en tomo a los ures importantes cambios ocurridos en estos veinte años: cl cambio cultural, cl cambio eclesial y el cambio sociopolítico. Los tres han aparccido constantemente a lo largo de estos días, y yo espero que, tras haber pasado por cllos, no sin desconcierto o dolor, la tcología de la liberación pucde seguir repitiendo (no sin humor) aquellas famosas palabran de don Juan Tenorio: "los mucrtos que vos matasteis —gozan de bucna salud". 
Este triple cambio nos ofrece, pues, las tres partes de esta charla. Pero quedan al menos dos temas que, en las prisas de mi redacción, no me entraban claramente en ese tiple esquema, pero poseen suficiente importancia como para que sea necesario recogerlos. Aludiré a ellos en dos apéndices. Pero repito: el carácter de apéndices no les viene de su escasa entidad sistematizable, sino de mi insuficiente habilidad sistematizadora. Quede esto claro.

\section{El cambio cultural}

Voy a comenzar por el cambio cultural porque creo que afecta a los otros dos, aunque éstos tengan evidentemente su autonomía. Ese cambio cultural podemos calificarlo de manera rápida y sencilla como paso de la modemidad a la postmodemidad. $Y$ eso para nosotros signilica el paso de un mundo que no queria resignarse ni siquiera ante la finitud, a un mundo que se resigna incluso ante el pecado. El paso de creerse prometeos a lo que Camus llamó "imaginarse a Sísilo dichoso".

Aunque yo dudo de que en América Latina pueda hablarse estrictamente de "postmodemidad" (por el elemento narcisista típico de la postmodemidad europea), sin embargo, muchos de los datos evocados por Garretón (crisis de los modelos revolucionarios, derrumbe del modelo que creía compatibles el crecimiento y la redistribución social..., como la misma adición de la "felicidad" a los gritos revolucionarios de libertad e igualdad), pueden entrar en la definición que acabo de dar. La diferencia está en que, en el primer mundo, este cambio es fruto de "mayo del 68" que ayer evocó Víctor Codina, y está tipificado en sus hijos, como ahora veremos. Muchos europeos leyeron la teología de la liberación como otra variante de mayo del 68 (la alusión de A. Bolado a la edición francesa de las ponencias del 72 aqui en El Escorial, remitiendo en una nota a Fernando Belo, es suficientemente expresiva de ello). Por eso conviene adelantar de entrada una primera tesis-balance, importanie para el futuro: la teología de la liberación no tiene nada que ver con mayo del 68. aunque naciera en fechas muy proximas y -en sus inicios - quedara más o menos salpicada por él.

Mayo del 68 fue una demanda adolescente de una plenitud imposible y facilona. Demanda que procedía de lodos los "niftos-bien" y marxistas bien alimenlados que poblaban las universidades europeas; y que se dirigía contra el mismo sistema que los habia hecho privilegiados (aunque no felices). Pero se alzaba contra el sistema no por solidaridad con las víctimas, sino para "ser realistas pidiendo lo imposible".

Y esta afirmación vale incluso del 68 de Estados Unidos, donde hubo matices más diversos que en Europa por la presencia en aquella sociedad tanto de los negros como de la guerra del Vietnam. Pero, aun en Eslados Unidos, acabó 
dominado el grito de Marcuse que anunciaba "cl final de utopía" (por su próxima conversión en realidad, en "topos"), frente al grito de las víctimas.

Y lo que ocurrí ya lo sabemos: en lugar del final de la utopía, la desaparición del horizonte utópico.

Voy a citar como testimonio de esta postmodemidad el "Manifiesto de mi generación" escrito a los 24 años, por David Leavilu, un chaval nacido hacia 1963, hermano menor por tanto, de los protagonistas del 68. El autor reconoce que el ideal de vida de sus padres había sido casarse, e ir teniendo "casas cada vez más grandes" y "el bungalow en Florida", pero que "ahora que ya alcanzaron los años dorados tan anhelados se hallan atrapados en matrimonios infclices o divorciados, y están demasiado amargados para tomar en consideración la idea de volver a amar o de un nuevo compañero". Después de esto explica que sus hermanos "cuando tenían mi misma edad... habían estado en la India, en Guatemala, en Cuba. Habían trabajado en la cárcel, habían organizado huelgas de braceros agrícolas...". Y continúa: "yo no siento ningún desco de este tipo ni tampoco, creo, la mayor parte de mis coetáneos. Más que movernos nos hacemos una madriguera. Nos interesa la estabilidad, el orden, el estar seguro. Queremos bellas casas, empleos satisfactorios y buenos amigos de uno y ouro sexo... En cambio, si a mi edad alguien hubiera preguntado a mi hermano qué querian, probablemente habrían respondido... ver el mundo e impulsar cambios radicales".

A lo largo del manifiesto de David Leavitt aparecen algunas posibles causas de esta mentalidad: por un lado "tenfamos tanto que ellos ni siquiera podían inaginárselo en su niñez". Además, "cuando mis padres se gritaban, sus gritos sonaban como laceraciones en aquel tejido de la perfección. Mis amigos se sentaban en el autoservicio de nuestra escuela media, leyendo libros de vivos colores, tilulados El libro del divorcio para niños.

En cualquier caso, las consecuencias en cambio de mentalidad, las describe también nuestro autor: "Nosotros no perdemos la razón porque para nosotros el pensamiento de un mundo sin futuro nos es completamente familiar... No es nada nuevo... Si no tenemos pasiones ni alectos es porque hemos decidido que pasiones y afectos no valen la pena. Si estamos agazapados en la sombra de una historia en la que nos negamos a participar, es porque ahí precisamente es donde hemos elegido estar".

El mismo reconoce que "tras esa amargura y escepticismo" está latente "una necesidad de estabilidad y seguridad". Pero argumenta: "nuestros hermanos y hermanas mayores (creian poder satisfacer esa necesidad) mediante la vida comunitaria y la revolución. Nosotros hemos visto dónde llevan estas altemativas. Nosotros tenemos confianza en nosotros mismos y en el dinero".

Me he alargado en esta cita porque creo que explica como pocas la evoluUniversidad Centroamericana José Simeón Cañas 
ción y autocrítica de los prolagonistas de mayo del 68, y su conversión a la derecha. Así, en el giro de la modernidad a la posunodernidad, se ha pasado de un liberacionismo egótico a una resignación egótica: de la aceptación de la contingencia a la aceptación de la injusticia y el pecado. Y a eso, la teología de la liberación le sigue oponiendo un famoso grito de Helder Cámara que está en sus origenes: (Los cristianos) "nos resignamos ante la voluntad de Dios, no ante las injusticias de los hombres". Creo que uno de los méritos de J. L. Segundo ha sido precisamente el esfuerzo por distinguir ambas resignaciones, y por combatir toda religión que pretenda identificarlas.

Repito pues: la teología de la liberación no nació de la experiencia del límite, sino de la experiencia de las vícuimas, de la experiencia del reverso de la historia, de la "irrupción del pobre" (G. Gutierrez). Si no se comprende csto se la malentenderá radicalmente. ( $\mathrm{Y}$ yo me temo que algo de eso le ocurrió al teólogo Rabzinger, que no tenía más experiencia de praxis liberadora que la de aquellos "manxistas bien alimentados" que hacían strep-tease en las aulas de la universidad de Tübingen, donde êl y yo coincidimos por aquellos años).

Esto implica como segunda tesis que la Teologia de la Liberación debe procurar desprenderse de todo resabio o reflejo que pudiera asimilar al 68 (quizá no por culpa suya, sino por la del imperialismo cultural del primer mundo). Creo que ya lo ha hecho, pero puede ser útil proclamar esto. Util sólo por razones pedagógicas, por más que, a la vista de la situación de las masas latinamericanas, resulıa más bien sarcáslico.

La categoría que hemos encontrado aquí estos días para hablar de ella es la del caminar (C. Bravo, Jon Sobrino), frente al paraíso de la modemidad y al pequeño rincón seguro de la postmodemidad. En este sentido, la teología de la liberación no es modema ni postmodema: su crítica al sistema no cs la de una razón histórica (aunque pueda dar origen a clla) ni la de los privilegiados que aún no tienen bastante, sino la de los oprimidos. Su protesta no es la de Adán que quiere ser como Dios, sino la protesta de Dios que quicre que todos los "adanes", todos los hombres sean sus hijos. Esta ambigücdad perdurará siempre, pero nunca será razón para abandonar.

Por desgracia, el deslino del 68 ha pesado con enorme negatividad en los juicios europeos sobre la teología de la liberación, aumentando de rebote la opresión porque, como reconocía David Leavitt, el mundo desarollado "deja de creer en el futuro para creer sólo en el deseo". Por eso conviene añadir que ese mismo primer mundo, que proclamaba su falta de fe en todas las utopías, ha seguido creyendo en una utopía inconfesada que es la utopía "tecnológica" o "tecnotrónica", como la llamó X. Gorostiaga. Esto nos llevará al tema del "conocimiento sin amor" que retomaremos en la tercera conclusión. Ahora me limito a subrayar que en esa utopia tecnológica se cree hoy como en un más allá que justifica todos los.medios. Al Dios de la opresión no le sustituye cl verdadero

Universidad Centroamericana José Simeón Cañas 
Dios de los pobres, sino el que Oriana Fallaci llama "el dios computer", tan omnisciente, omnipresente e infalible como despiadado. Y el hombre que adora a ese dios es cl que acaba descubriendo que "los hombres saben construir carreteras y puentes y casas y pintar la capilla sixtina y escribir el Hamlet y componer el Nabuco y trasplantar corazones e ir a la luna, pero son peores que los animalcs".

No saben ni quieren acabar con la miseria y la injuslicia, sino que la multiplican y, por eso, "con que si tienes un poco de cabeza o, mejor dicho, de corazón, no te agrada haber nacido entre los hombres... Si señores, es el hombre, no cl mundo, $\mathrm{cl}$ que, rico o pobre, no cambia. Es el hombre no el mundo el que culto o inculto no funciona" (Insahalla, 435-36 y 656).

No cambia el hombre, pero quizás degenera. Y además hace degenerar al mundo. Por cso, yo me atrevo a cerrar este capítulo afimando que - veinte años después- parece que la reología de la liberación no ha hecho mós que retomar y recolocar esa categoria tan cristiana y tan desprestigiada hoy (aunque a la yez tan compleja): la noción de pecado.

\section{El cambio eclesial}

En segundo lugar, también la Iglesia parece hoy muy seriamente amenazada por la tentación de otro cambio, desde el 72 al 92 . Alvarez. Bolado evocó que, en la preparación del encuentro anterior, hubo cierta colaboración del CELAM en la selección de invitados y que eso era hoy impensable. Comblin dio imágenes gráficas (además de ejemplos) de esa Roma que no escucha, malentiende y reprende. Si C. Bravo habló de la Iglesia como "comunidad de recuerdo" y de la relación entre identidad y memoría ihabrá que descubrir ese cambio diciendo que la Iglesia está olvidando esa "memoria de un vencido" que la constituye, para sustituirla por una apelación autoritaria a una sacralidad sin contenidos?

Podría ser. También podríamos hablar con R. Muñoz del paso de una Iglesia trinitaria a una Iglesia arriana o monarquiana. Pero yo preferiría ahora retomar la autocrítica hecha por J. L. Segundo, que acusó a la teología de la liberación de haber olvidado en demasía sus prolundas raices en el Vaticano II, para volverme al pasado Concilio, sobre codo a la Constitución sobre la Iglesia en el mundo, y definir entonces el cambio eclesial como paso de una Iglesia servicial a una que "se aferra como bolín a su imagen divina" (cfr. Fil 2,6ss) para decirlo con palabras del Nuevo Testamento.

En 1972, estaba aún reciente el Vaticano II y su anhelo de una Iglesia que consideraba como propios los dolores y las esperanzas de los hombres, sobre todo de los más pobres. Hoy —en mi opinión-domina en los eclesiásticos una actitud eclesiocéntrica, de autoafirmación desesperada, fruto del miedo ante la credibilidad perdida.

Digitalizado por Biblioteca "P. Florentino Idoate, S.J."

Universidad Centroamericana José Simeón Cañas 
Este cambio puede ser doloroso para la teología de la liberación que trató precisamente de teologizar los dolores y las esperanzas de los más pobres. En mi modesta opinión, la teología de la liberación sólo comenzó a preocupar en Roma cuando comenzaron a verse sus consecuencias eclesiológicas, es decir, cuando se comprendió qué significaba "hacer suyos los dolores y las esperanzas de los más pobres" (GS 1). Todo lo que dijo aquí Metz sobre el fín de la inocencia política y el fin del eurocentrismo, constituye, sin duda, una amenaza para un centro eclcsial tan instalado hoy en una presunta $-\mathrm{e}$ imposible - inocencia político social, y tan obstinadamente eurocéntrico (por no decir romanocéntrico).

En este sentido, el período que va del 72 al 92 está marcado por dos efemérides dolorosas, ambas evocadas aquí estos días: la cadena de conflictos enure la Confederación Latinoamericana de Religiosos (CLAR) y el Concejo Episcopal Latinoamericano (CELAM) recordados también por J. Comblin (y empleo la palabra conflicio como un eufemismo para aludir a acluaciones sumamente tristes); y los dos documentos vaticanos sobre la teología de la liberación, analizados por J. L. Segundo, y que cabe resumir así.

El primer documento (de 1984) daba la impresión de que, ante la "irmupción del pobre" (G. Gutiérrez) la Iglesia sólo era capaz de ver una corrupción sistemática de su identidad (¿olvidaba que ya en el siglo pasado, F. Ozanam había definido al Dios cristiano como "el Gran Pobre"?). En cualquier caso, esa sensación de comupción de su identidad explica el tono globalmente desautorizador y sin matices del documento. Ese tono es la mejor señal de hasta qué punto la institución eclesial se había creido amenazada. Pero el problema es que uno se cree amenazado también, siempre que es llamado a una conversión profunda. Y por tanto la sensación de amenaza costituye un argumento decisivo en contra.

La segunda Instrucción fue calificada por Jon Sobrino como "reconocimiento y desconocimiento", y me parece una calificación muy exacta. Esto quiere decir que también cuando - con la mejor voluntad- el Vaticano quiso ponerse positivo, también entonces malentendió la teología de la liberación: sólo le salió un discurso moralista y patemalista, con algunas estrellas fugaces.

No es problema, pues, de malas voluntades personales que podrían ser corregidas en ouras personas. Más aún, para jugar del todo limpio yo no tengo inconveniente en reconocer que conozco un escrito en que se proponía una utilización láctica de la fuerza de la Iglesia para una determinada causa política. Pero este hecho era rechazado por los teólogos latinoamericanos por los que yo tuve noticia de él; y hoy su mismo autor está de vuelta de semejante postura. Datos así, sí que pueden suscitar una legítima sensación de amenaza: pero eran golondrinas que no hicieron verano.

No se trata, pues, ni de malas voluntades personales, por un lado, ni de Digitalizado por Biblioteca "P. Florentino Idoate, S.J."

Universidad Centroamericana José Simeón Cañas 
amenazas ilcgítimas, por el otro. En mi opinión se trata de un problema más estructural, una especie de cegucra en la institución que - a mi modo de verse corresponde con el hecho de no haber llevado a cabo aquella "ruptura epistemológica" (G. Gutiérrez) de la que ya se habló en el 72 y fue evocada por A. Blanch al comienzo de estas jomadas.

La ruptura epistemológica no es un eslogan vacio que se hace evidente a base de repetirlo. Sino una experiencia que proclama como constitutiva todas las teologías hechas desde los pobres y desde los sulicientes (la teología política de Met\% - reconoce su "dejarse interrumpir por las víctimas"-, la tcología latinoamericana, las tcologlas asiáticas y africanas de la liberación, la ultimísima "leología de la marginación"...). Nosotros mismos hemos de comprender que, sin pasar por esa "noche oscura" que es la ruptura epistemológica, hay pseudolcologías de la libcración que pueden convertirse en simples fundamentalismos liberacionales. Ojalá nos ayude a esta experiencia lo dicho por Jon Sobrino sobre el marurio, y sobre la novedad (que es una novedad vicjísima porque es novedad jesuánica) de esos mártires latinoamericanos que lo son en defensa de los martirizados sin nombre (del pueblo crucificado). $Y$ son márures no para que tranquilicemos nuestra conciencia beatificándolos y dándoles culto, sino como visibilización de los martirizados desconocidos.

Qucda pendiente en estos momentos si todo este cambio en negativo va a continuarse en la asamblea del CELAM de este año 92, de modo que pudiera hablarse también de un paso de Medellín-Puebla a Santo Domingo. Dios no lo permita. Pero -en cualquier caso- sí que parece claro - desde las perspectivas de la teologia de la liberación- que el eslogan eclesial de este año 92 sobre la "nueva evangelización" pone a la Iglesia ante el dilema de si esa evangelización es concebida como una llamada de Dios que obliga a "salir de la patria y la parentela" propias, para llegar a ser Iglesia de los pobres, o si, por el contrario, la nueva evangelización se convertirá en una excusa para mantener posiciones privilegiadas o autoritarias en la Iglesia, y evitarle así el cristológico "anonadamiento" por los hombres. Tentación vieja, que ya lue denunciada por Gandhi, cuando acusaba al cristianismo occidental de "haber renunciado a vivir como Cristo, para poder anunciar a Cristo".

Pero todos los peligros anteriores no son un balance eclesial completo. Tal como nos presentó $R$. Muñoz, existe la iglesia anónima en medio de la Iglesia institución: no distinta de ella ni en ruptura con ella, pero sí escondida en ella, como san Ignacio decla que "la divinidad se esconde" en Jesús. Esa Iglesia anónima - como decía Ronaldo- se actúa en la relación de las comunidades con el pueblo, y se vuelve sacramento de Dios a través de las cinco dimensiones presentadas por él (samaritana, hogar, santuario, misionera y profética). No se trataba de idealizar nada, ni de caer en pinturas de blanco y negro; pero quizás cabe decir que los hombres reciben all mejores ejemplos y más esperanza. Y Digitalizado por Biblioteca "P. Florentino Idoate, S.J."

Universidad Centroamericana José Simeón Cañas 
esa Iglesia puede que sea uno de los mejores balances a hacer desde el 72 hasta hoy: el progreso de Dios en cl aparente retroceso de sus hombres. Pero, para descubrir ahí a Dios es neccsaria otra vez esa sacudida epistemológica que abre nuestros ojos pegados, y nos hace reconocemos en aquellos discípulos de Emaus que, precisamente cuando estaban ya al lado de Jesús, seguían diciendo: "nosouros esperábamos..." y ya no esperamos.

¿Será verdad entonces que, después de haber hablado de la noche oscura eclesial, podemos añadir ahora con el mismo san Juan de la Cruz: "oh noche amable más que la alborada"? Dios lo quiera.

\section{El cambio sociopolítico}

El lin de la guerra fría y la caída de los regimenes del este, constituyen un acontecimiento mucho más reciente, que todavía no pucde ser Icído con exactitud, y del que brotan dos expectativas: una negativa y otra positiva. Digamos a modo de lesis que el fin de la guerra fría puede conducir o al imperio caliente $o$ al diálogo cálido. Sólo la scgunda de estas dos posibilidades será benéfica para los pobres de la ticra.

\subsection{De la guerra fría al imperio caliente}

La caída de los regímenes del este puede suponer un nuevo desvalimiento para la teología de la liberación. Pero no porque ésta hiciera de ellos su apoyo y su modelo (como pretendían interesadamente los enemigos de la teología de la liberación), ni tampoco porque haya mostrado que la clase obrera no es el sujeto de la historia (véase cómo habla Ignacio Ellacuría sobre el sujeto de la historia en su Filosofta de la realidad histórica. y recuérdese qué bonitamente habló ayer Pedro Trigo sobre este punto, para comprender que los teólogos de la liberación no pensamos en "sujelos esenciales" de la historia). Si, en cambio, porque significa la crisis de los modelos políticos de cambio global y -hoy por hoy- de los modelos redistribucionales por vía confrontativa (Garretón). Y además porque lo que antes era un enemigo de los ricos se convierte ahora en un competidor de los pobres (Gorostiaga). El sistema productor de pobres queda ahora solo, sin enemigos, sin cuestionamiento, sin amenaza y sin desenmascaramiento. Se pretende entonces que el fracaso del este redima la vergüienza del oeste. $Y$ un sistema sin vergüenza se convierte en lo que he llamado "imperio caliente".

$Y$ esto ocurre tanto a niveles internacionales como nacionales.

\subsubsection{A niveles internacionales}

A nivel mundial se concreta esto en la noción de Estados Unidos de América Digitalizado por Biblioteca "P. Florentino Idoate, S.J."

Universidad Centroamericana José Simeón Cañas 
como gendarme de la historia, que impone sus propios intereses como ética mundial y sus propios enemigos como mal moral absoluto. La práctica de las "dobles medidas" (Kuwail y Panamá por un lado, Haiitú y Sarajevo por otro), o la reciente declaración del tribunal supremo de Estados Unidos sobre la legitimidad moral de la invasión de otros países para secuestrar a quien él considere peligroso, son ejemplos bastantes claros. El dominio casi absoluto de los cauces de comunicación permite además justificar y bcatificar una situación tan injusta, proclamando que con ella ha llegado "el fin de la historia", y dando a semejante estupidez una difusión mundial, mil veces superior a la que tiene -por ejemplo- la perduración... de la deuda latinoamericana (la cual, curiosamente, no aparece destinada a acabar con la historia).

Pues bien: Irente a esa mentira oficial, y aunque sólo sca con la voz ya exangüc del profecta molido, la lcología de la liberación debe seguir gritando aquellos versos de Casaldáliga: "democracia con hambre —es una flor encima de un cadáver". Y Dios no es un dios de los cadáveres, sino un Dios de la vida. La teología de la liberación deberó proclamar por eso que la constitución de un nuevo orden mundial es un mandamiento divino, al que la humanidad puede desobedecer acarreandose la muerse. Y que ese orden mundial ha de ser económico primero y político después: porque sólo así podría ser nuevo, y podrá ser orden y podrá ser mundial ("democralizar al Banco Mundial y al FMI", nos dijo Xavier Gorosuiaga).

En el campo político exige la sustitución del imperio mundial por la democracia mundial, y el esfuerzo por establecer uлa nueva autoridad mundial que sea distinta de la autoridad del que tiene mejor armamento. Exige, por tanto, la conversión de la Organización de las Naciones Unidas (ONU) en un verdadero parlamento mundial de iguales, una organización de naciones unidas (y no de naciones supeditadas), donde la autoridad está sobre todo para defender a los que menos defensa tienen.

Y en el campo económico exige cl trabajo por la constitución de un nuevo orden económico internacional en el que -como único cjemplo y primer paso- se comenzará por la abolición de la otra clásica "doble medida" en las relaciones económicas internacionales por la que - por ejemplo- los países ricos imponemos aranceles a los productos del tercer mundo, mientras los obligarnos a quitar sus aranceles a nuestros productos. Ese es el cćlebre mercado "adminisurado" o asimérico, que tiene de mercado lo mismo que la democracia orgánica de Franco lenía de democracia.

\subsubsection{A niveles nacionales}

Pero la amenaza del "imperio caliente" no se da sólo a niveles internacionales, sino también a niveles nacionalcs. La caída del este casi ha coincidido con Digitalizado por Biblioteca "P. Florentino Idoate, S.J."

Universidad Centroamericana José Simeón Cañas 
la aparición de eso que llamamos "cuartos mundos", con la aparición del lenguaje sobre la "democracia de baja intensidad" o democracia pasiva, y del fenómeno (mucho más complejo y quizás más determinante para el futuro) de las migraciones masivas e imparables. El fracaso del socialismo real se corresponde aś con la vergüenza del capitalismo real por más que se intente maquillar a ésta. Los pobres son los que juzgan la calidad humana de cada figura histórica, dijo P. Trigo. Y desde ellos afirmamos que ha fracasado un remedio, pero la enfermedad continúa. No se ha encontrado la vacuna, pero hay una especie de SIDA social en nuestro sistema económico. Buena parte de la desmovilización y de la falta de participaciớn ciudadana, que oímos lamentar cada vez más en occidente, proviene de esta sensación difusa de que el sistema está enfermo (aun cuando, seguramente, es una reacción que contribuye a aumentar la enfermedad).

Todos estos fenómenos, de los que sucesos como los recientes de Los Angeles son sólo primeros síntomas, esı́n haciendo nacer entre nosotros lo que ya se llama una "teología de la marginación", hermana de la teologia de la liberación y fruto de su semilla en nosotros. Otro fruto quizás de aquel 72, cuyo recuerdo nos ha convocado. Con ella, se comienza a cumplir una tarea que en Europa estaba pendiente: no limitarse a repetir aquí la teología de la liberación literalmente, sino inculturarla en nuestra realidad. Gorostiaga habló de la sociedad de "un tercio" (o democracia de un tercio) en el sur, frente a la sociedad de los dos tercios en el norte. Nuestros marginales, ese tercio excluído de csta sociedad de los dos tercios, son los modernos esclavos -indispensables para nuesuro progreso- y que, por ser minoría nunca podrán salir de su marginación por métodos democráticos. ¿Habrá que recuperar aquí todo lo que la teología patrística había dicho contra la esclavitud (y no lo que dijeron a su favor los teólogos del sistema en el siglo XVII)? Y conviene proclamar que Occidente ha fundado siempre su progreso y su "civilización" sobre la existencia de los esclavos, los cuales sin duda son el medio más eficaz para un progreso meramente material y, por eso, fueron justificados por los filosofos griegos (apelando a la Naturaleza), por teólogos del s. XVII (apelando a una eficacia civilizadora necesitada para evangelizar-) y por los modemos defensores del sistema (apelando a la efícacia económica).

\section{2. ¿De la guerra fría al diálogo cálido?}

Estos son los peligros, pero no todo es negativo en la caída del Esle. Sin ninguna duda, hay que señalar una gran posibilidad abierta, la cual es fruto, a la vez, de la unidad que va adquiriendo el mundo, de la modestia de la cultura postmoderna y -en la Iglesia- de la aparición de las teologías asiáticas y africanas: me refiero a la categoría del diálogo, la cual (como solemos decir los teólogos) sólo es don en cuanto es a la vez una tarea. En ella parecen confluir los tres capitulos de esta conclusión.

Digitalizado por Biblioteca "P. Florentino Idoate, S.J."

Universidad Centroamericana José Simeón Cañas 
El fin de la guerra fría puede ser lambién el comienzo del diálogo cálido. El diálogo es una categoría humana, política, social y religiosa. Y, ciñéndome a este último aspecto, quiero señalar la gran importancia de lo que estŕ sucediendo en Asia, por las búsquedas de sintesis entre las teologías de la liberación y las teologías del diálogo interreligioso. Quisiera volver a cilar el nombre de Aloys Pieris como ejemplo de esa tcología-en-promesa, en la que la liberación de los pobres y el diálogo interreligioso "se besan" como la justicia y la paz en la oración bíblica. Y tanto Diego Irarrazaval como Víctor Codina han puesto de relieve hasta qué punto ese diálogo asiático es también necesario con las culturas y religiones indigenas de América Latina, si bien parece mucho más difícil porque esas religiones no están tan identificadas en textos sagrados y autoridades reconocidas, como en el caso de la India.

El balance de esia evocación veloz de las tcologías asiáticas es, para mí, que, asi como hace veinte años se comenzó a hablar de la opción por los pobres y la lucha por la justicia como "exigencia absoluta" de la fe y como distintivo de la fidelidad de la Iglesia a Jesucristo, ahora, sin dejar absolutamentc nada de aquello, hay que añadir otra exigcncia: el diálogo como "exigencia absoluta" de la $f e$. Y, desde aqui, lo que Gorostiaga calificó como un "ecumenismo humano".

Y lo que me parcce más imporlante notar es que, en csta interacción, la calcgoría misma del diálogo queda transformada. En la medida en que ella -igual que la lucha por la justicia- brota de esa "fe informada por el amor" con la que Dios justifica al hombre, hay que aplicarle aquellas palabras de san Ignacio: "el amor (y ahora el diálogo) se debe poner más en las obras que en las palabras". En un primer momento se podria pensar que los universos oriental y occidental son tan distantes que no hay diálogo posible. Por ejemplo, desde la tremenda insistencia del oriente en la interioridad y desde su total relativización de lo exterior (mayâ, samshara, elc.) puede parecer que la teología de la liberación no tiene sentido, o que estamos ante recursos conservadores para eludirla. Creo, sin embargo, que tanto el primer mundo como el mundo latinoamericano neccsitan enormemente la riqueza intcrior y las experiencias de interioridad del oriente. Pero no para quedarse en ellas, sino para vaciarse desde esa riqueza interior, como se anonadó Cristo desde su Intimidad Divina. A la kénosis (vaciamiento) de Dios sigue así la kénosis del hombre (el Purscha de los texlos hindúes) que es lo que América Latina puede aportar al oriente. La mística de los ojos cerrados se convierte aquí en lo que Mctz calificó como una "mística de los ojos abiertos".

Y anonadamicnto o vaciamicnto ipor qué? Pues porque antes cl corazón dc Dios sc ha vuclto hacia esa "mentira" exterior (hacia esa "mayâ") para enriqueccrla con su cmpobrecimicnto (cfr. 2Cor 8,9). "Nosotros somos nada", clamaba hace ya siglos san Bcrnardo. Y aún añadía que menos que nada, dado que somos maldad y pecado. Pcro lucgo sc pregunlaba: “¿cómo pucde ser nada Digitalizado por Biblioteca "P. Florentino Idoate, S.J."

Universidad Centroamericana José Simeón Cañas 
aquel al que Dios engrandece, aquél al que se ha vuelto el corazón de Dios?". Y concluia: "somos algo pero lo somos por su dignación, no por nuestra dignidad" (illius dignatione, non nostra dignitate). Aquí está lo que, en mi opinión, distigue al cristianismo, tanto de la dignidad "modema" del hombre, como de la anulación oriental de la historia.

Y aqui empalmamos con lo antes insinuado de san Ignacio, de poner el amor más en las obras que en las palabras. Lo que acabo de decir implica para la categoría del diálogo, la oferta del ejemplo antes que la imposión de la palabra. Y aquí aparece otra lección de la teología de la liberación: ella ha intentado - si se me permite la expresión- actuar como Dios más que hablar de El; ha querido "hablar de Dios".

En este sentido la teología de la liberación ha tenido siempre algo de "teología apofática". Por extraño que esto pueda sonar, creo que no es más que la reivindicación de la pneumatología que hizo ayer V. Codina. El Espíritu no explica: clama con gemidos inenarrables -con "obsesión"- y hace acluar: es el apofatismo de los escritos joánicos que insisten tanto en que a Dios nadie le ha conocido ni entendido nunca, y que decir que se ama a Dios es un engaño; pero sin embargo, revalidan el conocimiento de Dios y el amor a Dios en la experiencia del amor fratemo, que es la obra del Espíritu en nosotros. Desde aquí, la teología de la liberación tiene un puesto para el diálogo de la Iglesia con los otros universos religiosos. Recordemos todo lo que hace 20 antos decía Gustavo Gutiérrez sobre la teología como "acto segundo" y sobre la primacía de la praxis. ¿Por qué?, ¿por un desprecio postmoderno esteticista de la tcońa? No. sino porque la teología de la liberación sabe bien que -como escribió san Gregorio de Nisa- "todos los conceptos que nos hacemos de Dios con el entendimiento crean ídolos en lugar de recordar a Dios mismo" (podemos añadir que incluso los conceptos del magisterio eclesiástico por necesarios que sean). Y saben también que el único nombre para expresar a Dios es -como añadía el mismo Niseno- el asombro. Pero no sólo el asombro del que se queda callado ante la immensidad de lo positivo, sino también y en primer lugar el asombro del que se queda estremecido ante la cruz de Jesús y la maldad del mundo que lo mata y -desde ellas - ante los crucificados de la tierra. El asombro de la crucilixión del hombre. Y por eso, desde ese asombro, la tcología de la liberación no se limita a quedar callada en el éxtasis, sino que se vuelve activa en la solidaridad; $y$ en esa solidaridad pronuncia una tímida palabra sobre Dios.

Desde esa solidaridad recuperamos la noción de Jon Sobrino de la teología de la liberación como intellectus amoris, para desde ahí recuperar tambićn la crítica de la razón occidental como "conocimiento sin amor". Deliberadamente tomo esta expresión - "conocimiento sin amor" - de un importante científico europeo (Karl F. von Weiszäcker) a quien voy a citar para concluir. Si quieren, ustedes pueden contraponerla a las palabras del cubano J. Martí que citó Digitalizado por Biblioteca "P. Florentino Idoate, S.J."

Universidad Centroamericana José Simeón Cañas 
Gorostiaga: "por el amor se ve, con el amor se ve".

Pues bien, según von Weiszăcker, el yo en el cristianismo es siempre "un yo libre frente a un tú". Esta concepción va desapareciendo al nacer la racionalidad modema en la que el sujeto es tal siempre frente a un objeto. Así, escribe von Weiszäcker, "desaparece el amor pero queda el conocimiento, y el projimo deja de ser considerado como sujeto".

Añade luego nuestro autor que "el mundo científico y técnico de la edad moderna es el resultado de la aventura humana del conocimiento sin amor". Tal conocimiento no es necesariamente malo (por eso nuestro científico habla de una "aventura"): puede ser bueno según a qué poder sirve. Pero concluye: "si ese conocimiento sin amor entra al servicio de la resistencia contra el amor, retrocede al punto que en el cuadro mítico del cristianismo se llama Demonio". El conocimiento sin amor es entonces la tentación de la serpiente en el paraíso, es la obra del Anticristo que da la batalla "para aniquililar al Amor", pero - concluye Weiszäcker- "por supuesto, es el Poder el que se autoaniquila con la victoria" (Historia de la naturaleza, Madrid 1962, pp. 242-243).

\section{APENDICE I}

\section{La discusión pueblo sujeto-pueblo objeto}

A lo largo de estos 20 años, se ha plantcado en América Latina una discusión que también se ha reflejado aquí; y era conveniente que se reflejase, si este congreso habia de entroncar con la realidad y reflexionar sobre ella. Simplificando mucho, la podemos titular así: los pobres ¿son objeto o sujeto de la teología y de la Iglesia?

Lo que está aquí en juego es, por un lado, la necesidad de liberar a los pobres pero, por el otro, la necesidad de no colonizarlos so pretexto de liberarlos.

El temor de que un respeto excesivo a lo popular no descubra lo que los oprimidos tienen introyectado de los opresores, no es un temor infundado ( $y$ esto no lo dice Marx, sino Paulo Freire). El todopoderoso sistema puede utilizar conservadoramente un afán inculturador de tal modo que la inculturación en una cultura oprimida se convierta en identificación con la opresión. Pero una liberación impuesta no es liberación. Yo quisiera seffalar que aunque esta polémica parece interior a la teología de la liberación es tan lógica que se reproduce en la polémica africana -cilada por Julio Lois- entre inculturación y liberación. Pues bien, se ha dicho que toda inculturación tiene que transcenderse y que toda liberación no puede imponerse, sino que debe encamarse.

¿Cómo salir de aquí? Mi maesuro Juan Luis Segundo aconseja en alguna Digitalizado por Biblioteca "P. Florentino lodoate, S.J."

Universidad Centroamericana José Simeón Cañas 
parte que cuando nos encontremos ante alguna oposición lógica tratemos de pensarla procesual o evolutivamente. Yo quisiera aceptar ese conscjo, pero añadiendo que pensar evolutivamente es ya una manera "oscuramente primordial" de pensar pneumatológicamente.

Pues bien, si pensamos pneumatológicamente quizás quepa decir que es la acción del Espíritu la que hace a los pobres lugar teológico. Quizás no lo serán ellos solos por su pobreza. Como también la cruz de Jesús es lugar teológico fundamental, pero no por su dolorismo (¡Jesús muere gritando el abandono de Dios!), sino porque Jesús muere "por el Espíritu Elemo" (Heb 9,14). Pues bien, algo semejante puede ocurrir con los pobres. A mí me parece que son reales las experiencias sorprendentes de su calidad en su falta de calidad, de su "Gracia en la desgracia" (como dice Luis García Orso). Y esta realidad se convierte en un sacramento y anuncio de la liberación posible, en lugar de ser un motivo para renunciar a ello.

Así es como podemos, a la vez, evangelizar a los pobres y ser evangelizados por ellos.

\section{APENDICE II}

\section{La alternativa remenina}

Por razones ajenas a mi voluntad, y que tienen que ver con la "tiranía" de los medios de comunicación, no pude estar en la ponencia de Ivone Gebara. Me limitaré, por lo lanto, a comentar no su contenido, sino el signficado del hecho. (Como dirfa Bulumann: no el "Was" sino el "Dass").

El hecho de la presencia de una mujer es ya teológicamente significativo. Por supuesto, cuantitativamente es ínfimo, al lado de esta injusta "mayoria absolula de varones"; pero cuantitativamente, el paso de la nada al ser es mucho más que el paso de uno a dos, tres o diez. En el encuentro anterior de 1972 no hubo ninguna mujer entre los ponentes.

Los organizadores quizá pensábamos en una ponencia de reivindicación femenina. Creo que aquí se ha pasado tambiên de reivindicación a alternativa. Una altemativa que no es sustitutoria, pero sí complementaria y que, al complementar, transforma. Una posibilidad de altemativa que pone en evidencia hasta qué punto la teología hasta hoy ha sido - no voy a decir "homosexual", pero sí homo-lógica-, y cómo debe pasar de una homo-logía a una helerología para que se cumpla aquel célebre dicho del Génesis que voy a evocar para concluir: el téblogo adámico dejará su logos "paterno" y se unirá al logos de la que fue llamada "madre de los vivientes", para llegar a ser "una sola teologia".

Sólo así la teología acercará a Dios en lugar de desfigurarlo y se cumplirá el Digitalizado por Biblioteca "P. Florentino Idoate, S.J."

Universidad Centroamericana José Simeón Cañas 
comentario paulino al Génesis: "realmentc hay aquí un gran Misterio".

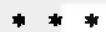

En conclusión, pues: la tcología de la liberación como intellectus amoris, la teología de la liberación como ruptura cpistemológica, y la tcología de la liberación como tcológica apơática o (para expresar mejor la paradoja) apofáticodialogantc, son tres grades tareas, tres grandes caminos que estamos empezando a recorrer, que pueden brotar como balance primerizo de eslos veinte años y cn las que yo creo incluso que podríamos coincidir todos los cristianos. Una vez dicho esto es evidente que todavia queda mucho, o casi todo, por cstudiar y por hacer. Pero ojalá que el haber tomado conciencia de esto nos ayude a seguir haciendo. 